\title{
The Causal Relationship between the Stock Indices of Western Bloc Countries: A Case on Belgium and France
}

\author{
Anjali Verma* and Treesa Joseph $\mathrm{T}^{\dagger}$
}

\begin{abstract}
The paper aims at finding reciprocity among two Western European Bloc indices CAC40 and BEL20. CAC40 is a French index which has been in existence since 1986 and BEL20 is a Belgian index whose calculation started four years later. A Granger Causality Test has been performed to check for causality relationships among both the indices. The dataset taken comprises logarithmic close prices on which Bivariate Granger Causality has been performed. The dataset spans for 20 years from 2000 to 2018. The study found the younger index BEL20 to be the driver index and CAC40 as the driven index. Thus, the conclusion drawn is that the performance of CAC40 depends on BEL20 most of the time.
\end{abstract}

Keywords: Bivariate Granger Causality, Co-integration and Linkages, Stochastic Drift

\section{Introduction}

The BEL20 ("BEL 20," 2018) is the benchmark stock market index of Euronext Brussels. It tracks the performance of 20 most capitalised and liquid stocks traded in Belgium. The BEL20 is a free-float capitalisation-weighted index. The weights of the constituent stocks are based on the market capitalisation adjusted for free float and

* Deloitte India; anjaliverma25895@gmail.com

† E\&Y India; treesajosephth@gmail.com 
the base value of EUR 1000 was fixed on 30 December 1990 and has a market capitalisation of 408.11 USD billion (as on 26 July 2018).

The CAC 40 ("CAC 40," 2018) stock market index in France records the performance of Top 40 stocks based on their market capitalisation. The launch of the CAC 40 corresponded with the French stock market changing to electronic trading in 1986. It represents a capitalisation-weighted measure of the forty most significant values among the hundred highest market capitalisations on the exchange indicating the overall level and direction of the market in France. The market capitalisation of CAC 40 Index is $€ 1572.86$ billion (as on 26 July 2018).

\section{Literature Review}

Samadder and Bhunia (2018), in their study, examined the shortrun and long-run linkages between the Indian stock market and selected developed stock markets of Australia, Canada, France, Germany, UK and the USA based on time series data for the period between 2001 (2 $2^{\text {nd }}$ January) and 2016 (31 ${ }^{\text {st }}$ December) by using the Johansen Co-integration Test. The results showed that both the Indian stock market and the USA stock market are associated in the long-run and it would take a long time to return to equilibrium. Furthermore, the Indian stock market is associated with France, Germany and the USA stock markets in the short-run.

Arunachalamand Srividya (2014) recorded the 10-year month-end closing logarithmic returns of BSE Sensex and Shanghai Composite Index for the period between 2005-2014 to identify the inter-linkage patterns between the two stock markets. The results show that the Indian stock exchange is more receptive to the Chinese stock exchange while the India-initiated advancements ward off rapidly in the Chinese stock exchange.

International researchers Rehman and Hazai (2014), in their study, investigated the existence of linkages between Saudi Stock Market Index (TASI) and the bigwig stock markets indices, namely, US, UK, Japan and Gulf Cooperation Council (GCC) on the data recorded from the $1^{\text {st }}$ of July 2004 to the $31^{\text {st }}$ of December 2008 for Period-I (This phase covers a substantial period of economic boom in Saudi Arabia) and from $1^{\text {st }}$ of January 2009 to the $31^{\text {st }}$ of July 
2013 for Period-II (This duration encapsulates major restructuring in the Saudi stock market sectors). The findings indicated that numerous causations between stock market indices have increased in Period-II. Therefore, these findings are pertinent for all investors at the domestic and international levels.

Niblock and Sloan (2006) examined the efficiency of the DJIA and the Chinese peers such as Shanghai $(A, B)$, Shenzhen $(A, B)$ and Hang Seng $(A, B)$ and found that the Chinese stock market was weaker in terms of efficiency regardless of a double-digit growth and consistent variation in the regulatory framework during the period between 2002 and 2005.

Hoque (2007), an international researcher, in his paper, aimed to investigate the linkages of stock price movements of an emerging market; Bangladesh with the USA, Japan and India by using the Johansen and Juselius Multivariate Co-integration approach. Findings indicated that there is a sign of co-integration among the markets demonstrating that there is a common stochastic drift among the stock prices in the countries studied.

An international research group, Baharumshah, Sarmidi and Tan (2003), in their work, investigated the dynamic linkages among the major stock markets in the four Asian markets (Malaysia, Thailand, Taiwan and South Korea), both in the short-run and in the longrun. The empirical results indicated that all the Asian markets are closely interlinked.

Similarly, Chen, Firth and Rui (2002) researched on linkages between the major stock markets in Latin America by using data between 1995 and 2000, partitioning the sample into periods before and after the Asian and Russian financial crises of 1997 and 1998. Findings hinted at a co-integrating vector which seems to describe the dependencies in prices and suggest that the potential for diversifying risk by investing in different Latin American markets is constrained.

An Indian research team, Kishor and Singh (2017), in their study, unveiled the effects of stock exchange indices' returns of BRICS on each other's stock returns. A significant and positive correlation among Nifty and other BRICS indices were observed in the study. It was found that international investors can reap benefits from the 
portfolio diversification. However, the impact of Foreign Institutional Investors (FIIs) and other related influences need to be analysed further in future studies.

Ahmedov and Bessler (2012) discovered another extremely intriguing finding in 2008 that amidst the crisis period, Hang Seng followed its global peers such as DJIA or DAX. However, this was not the case in Shanghai. There might be a certain connection between Shanghai and Hang Seng in both natural and inorganic ways. But it will be very hard to set up a connection objectively amongst Shanghai and DJIA or DAX.

Hsu, Horng, and Hsu (2012) studied the influence of the stock market on the stock markets of Hong Kong and Singapore. The empirical results indicated that the Canadian stock market drives or leads both the markets as it affects the variation risks of the stock market returns of Hong Kong and Singapore.

Guidi and Gupta (2010), in their study, explored interlinkages between the Indian stock market and three developed Asian markets (i.e. Hong Kong, Japan and Singapore). Co-integration methodologies were used to examine interdependencies. Results indicated that in the long-run, the benefits for investing in India are restricted.

Yusof and Majid (2006), in their study, investigated long-run comovements between the Malaysian stock market and the two largest stock markets in the world: the US and Japan, to understand which market actually led the Malaysian stock market before, during, and after the 1997 Asian financial crisis period. The findings proved that the Japanese stock market significantly moved the Malaysian stock market more as compared to the US stock market in the post-crisis period.

Yang, Khan and Pointer (2003) revealed that within the sample period of thirty-two years, from January 1970 to December 2001, a long-run relationship between the US market and most of the other international markets was not found. However, the study reveals a recent trend of increasing co-integration among the smaller markets and the US market whereas larger markets like Japan, UK, and Germany do not show any such trend with the US markets 
thereby enabling the US investors to diversify their portfolio in such larger markets.

Huang, Wang and Hu, 2000 in their work on South China Growth Triangle (SCGT) (tenure between 1992 and 1997) showed that there was no co-integration apart from two mainland Chinese bourses i.e. Shanghai and Shenzhen. Interestingly, they found a profound impact of the US markets on SCGT and a clear linkage between the US and the Hong Kong Markets.

An Indian researcher, Jain (2016), in his work, has utilised data for a ten-year-period to study the chances and intensity of the presence of linkages between the mutual fund and its respective benchmark by using Johansen Co-Integration Test and Granger's Causality Test. Findings indicated that the mutual fund and index are nonco-integrated and no Granger Causality was present.

Shen, Chen and Chen (2007), in their study, used the Granger Causality Test to investigate linkages between the Chinese Shanghai and Shenzhen stock markets. The results showed that both the stock exchanges have dynamic linkages.

Ghosh (2016) studied the Hang Seng and Shanghai Stock Exchange for the time period of two and a half decades to assess the chances and potency of the causal relationship between the two Chinese bourses. He used the Johansen Co-integration Test and Bivariate Granger Causality Test and arrived at the result of Shanghai Stock Exchange (SSE) as the lead or the driver index and Hang Seng (HSI) as the driven index. Earlier, in 2015, he conducted an indepth study to identify the driver and driven index patterns between Sensex and Nifty for a period between 29th October 2013 and 18th August 2014 using the Granger Causality method. The study found that there was no stochastic drift pattern and that arbitrage opportunities existed.

Hsu et al. (2012) studied the influence of the Canadian stock market on the stock markets of Hong Kong and Singapore. The empirical results indicated that the Canadian stock market drives both the markets as it affects the variation risks of the stock market return of Hong Kong and Singapore. 
Thalassinos and Politis (2011) carried out a study on similar lines applying Co-integration and Causality Tests to examine the efficiency of the PIIGS stock markets but taking two categories of indices i.e. European and Non-European (U.S.A, Canada, Singapore, Japan, and Hong Kong). The results indicated that during the last decade, there was a downturn in the number of stochastic trends that influenced the markets.

Choudhry, Lu and Peng (2007) in their paper investigated empirically the change(s) in the long-run relationship(s) between the stock prices of eight far east countries around the Asian financial crisis of 1997-1998. Findings based on causality tests showed the significant long-run relationship(s) and linkages between the far east markets before, during, and after the crisis.

Mukherjee and Bose (2006) investigated the co-movement of the Indian stock market with developed markets like the US, Japan and other Asian markets by employing Granger Causality tests. They worked with data from a period of January 1999 to June 2004. The results indicated that the degree of interlinkage found was not very high. This, therefore, implies that the nature of integration with emerging Asian markets does not assure any immediate concern for India with regards to possible contagion effect and also shows that there is much scope for reaping benefits by investing in Indian markets and diversifying the portfolio.

On the same lines, Wong, Agarwal and Du (2005), in their work, examined the long-run equilibrium relationship and short-run dynamic linkage between the Indian stock market and the stock markets of the United States, United Kingdom, and Japan post1990 by using the Granger Causality relationship and the pairwise, multiple and fractional co-integrations. Results showed that the Indian stock market is integrated with mature markets and is responsive to the dynamics in these markets in the long-run. In the short run, both the US and Japan drive the Indian stock market but not vice versa.

Tian and Wan (2004) explored causality on A, B and H shares (graded) by using a unique test of 'no-causality' and concluded that a strong link was only present in B-graded stocks of Shanghai and Shenzhen for a time period between 1993-1999. 
Similarly, Zhu, Lu, Wang and Soofi (2004) found a sign of causal linkage between Shanghai, Shenzhen and Hang Seng in their study. However, their work clearly mentioned scope for further research such as having a considerable length of time to make it more robust.

Narayan, Smyth, and Nandha(2004) used the Granger Causality Test to examine the inter-linkage pattern between the stock markets of Bangladesh, India, Pakistan and Sri Lanka and found that stock prices in India, Bangladesh and Sri Lanka drive the stock prices of Pakistan in the long-run.

Bessler and Yang (2003), in their work, concluded that the Japanese stock market is driven by the developed stock markets of the US, UK, Hong Kong, France and Germany.

Darrat and Zhong (2003) used weekly data from November 1987 through May 1999 to identify the main driving force between the US stock market and the Japan stock market (or both) causing major movements in the stock prices of the eleven emerging Asian-Pacific countries. The findings showed that the US rather than Japan is the main permanent force driving the equilibrium relations across all Asian-Pacific markets. On the contrary, the influence of the Japanese market on the Asian-Pacific region is temporal in nature.

Sheng and $\mathrm{Tu}(2000)$ used the Granger Causality Test to determine any driver and driven index pattern among twelve Asia pacific peers before and during the Asian financial crisis. They found that the US markets played a dominating role during the crisis.

Further, Kim and Shin (2000) studied the issue of causalities among five different indices of shares issued by Chinese firms, A and B Shares listed in the Shenzhen and Shanghai Stock Exchanges, and $\mathrm{H}$ Shares listed in the Stock Exchange of Hong Kong by conducting Granger Causality Tests. Findings were that the causality relationships among the five different indices went through significant changes after early 1996; B Shares became a driver relative to the other shares.

Smith, Brocato and Rogers (1993), in their study, examined the weekly returns during the period 17 January 1979 to 26 June 1991 
from markets in the US, Great Britain, West Germany and Japan to explore inter-linkages by using Bivariate Causality Tests and concluded that the sign of Granger unidirectional causality running from the US to the other countries immediately after the October 1987 world-wide crash was present.

\section{Research Methodology}

In this study, the time span of the series is twenty years. The closing price data of CAC40 and BEL20 were taken on a daily basis from 1998 to 2018. The total dataset consists of 5101 data points. A Bivariate Granger Causality Test is being used on the logarithmic values of the data set to observe and identify any patterns that might come up.

The Bivariate Granger Causality Test (Bai, Wong \& Zhang, 2010) is used to determine whether a time series is capable of forecasting another time series. The test is mainly used to identify the driverdriven relationships among the two-time series. The test had been performed on the logarithmic values in order to reduce the standard error.

The hypotheses for the Bivariate Granger Causality Test for twotime series $X(t)$ and $Y(t)$ can be given as:

$H 0$ : The lagged values in $X(t)$ do not explain the variation in $Y(t)$ [the series $X(t)$ does not drive $Y(t)$ ]

Ha: The lagged values in $X(t)$ explains the variation in $Y(t)-$ [the series $X(t)$ drives $Y(t)]$

The equation for Granger Causality for two-time series $X(t)$ and $Y$ $(\mathrm{t})$ is given as:

$$
\begin{aligned}
& Y(t)=\alpha+\sum_{i=1}^{p} a Y_{t-i}+\sum_{j=1}^{q} b_{j} X_{t-j}+\varepsilon_{i} \\
& X(t)=\beta+\sum_{i=1}^{r} c_{i} X_{t-i}+\sum_{j=1}^{s} d_{j} Y_{t-j}+n_{i}
\end{aligned}
$$

$\varepsilon_{i}$ and $n_{i}$ are the disturbances satisfying the regularity assumptions of the classical linear normal regression model.

$X(t)$ is said to not Granger cause $Y(t)$ if $b_{j}=0$, for any $j=1, \ldots q$. Similarly, $Y(t)$ is said to not Granger cause $X(t)$ if $d_{j}=0$ for any $j=1$, ..., s. 
Verma and Joseph The Causal Relationship between the Stock Indices

Here, for the analysis, there are no lags taken. Thus, the values of $p$, $\mathrm{q}, \mathrm{r}$, and $\mathrm{s}$ is 1 .

The dataset for the analysis had been taken from secondary sources (investing.com and The Wallstreet Journal website). The Bivariate Granger Causality Test had been carried out using online statistics and forecasting software - wessa.net (Wessa, 2018).

\section{Results}

X: CAC40, Y: BEL20

Table 1.0 Granger Causality Test $Y=f(X)$

\begin{tabular}{|c|c|c|c|c|}
\hline Model & $\begin{array}{l}\text { Res. } \\
\text { DF }\end{array}$ & Diff. DF & $\mathrm{F}$ & $\mathrm{p}$-value \\
\hline Complete model & 5096 & & & \\
\hline Reduced model & 5097 & -1 & 1.3819 & 0.23983 \\
\hline
\end{tabular}

P-value is higher than expected. Hence, the null hypothesis will stay (refer to Table 1.0).

Table 1.1 Granger Causality Test $\mathrm{X}=\mathrm{f}(\mathrm{Y})$

\begin{tabular}{lllll}
\hline Model & $\begin{array}{l}\text { Res. } \\
\text { DF }\end{array}$ & Diff. DF & F & p-value \\
\hline Complete model & 5096 & & & \\
Reduced model & 5097 & -1 & 44.5577 & 0 \\
\hline
\end{tabular}

P-value is lower than expected. Hence, the null hypothesis will not stay (refer to Table 1.1).
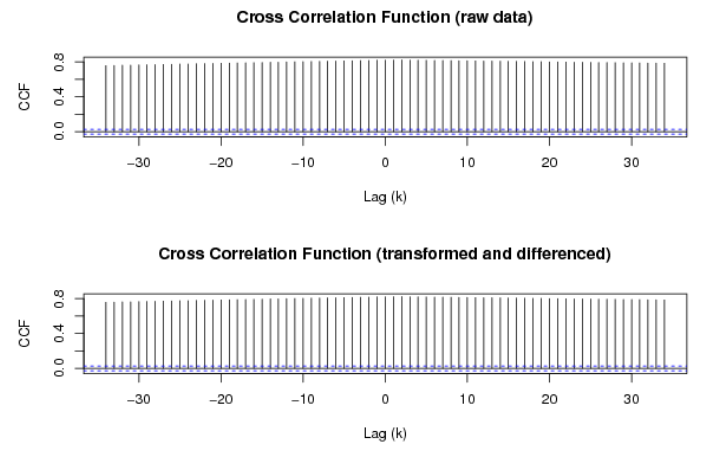

Fig 1.0 Cross- Correlation Function 


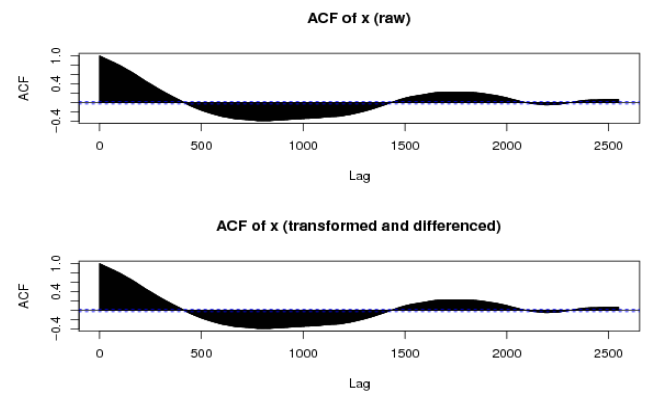

Fig 1.1 Auto-Correlation Function of X
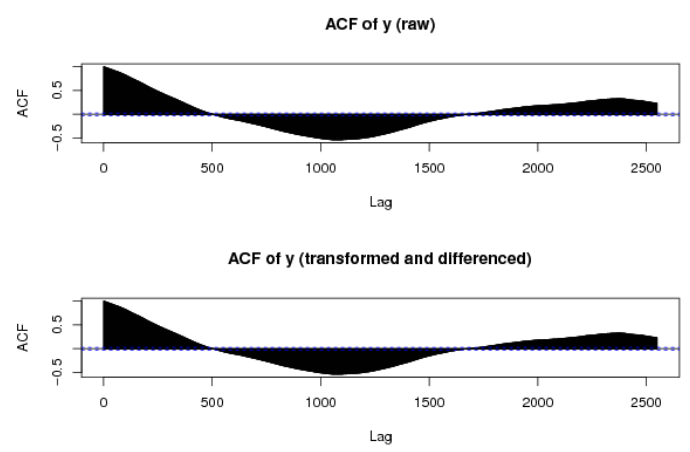

Fig 1.2 Auto-Correlation Function of $Y$

\section{Interpretations}

According to the Bivariate Granger Causality Test, NIKKEI is observed to be playing the role of a driver, whereas, TOPIX was driven by NIKKEI. TOPIX is dependent on the NIKKEI for $99.99 \%$ of the results and NIKKEI was driven by TOPIX for $89.77 \%$ of the results. Thus, TOPIX is driven by NIKKEI to a larger extent. The results can be said to be quite robust in nature since the volume of the data is huge and the dataset had seen many business cycles.

As per the ACF of the raw and transformed data, both the indices appear to follow the model of Moving Averages. For both the 
indices, the data has significant values even after 5-6 lags, implying that the time series for the same is non-stationary.

Cross-correlation function plot implies that the two waveforms are not in similar order (not self-similar). Also, the sides are tapered with the intensity being low.

\section{Conclusion}

BEL20 started from 1990 onwards, holds the twenty most voluminous Belgian stocks listed in Euronext Brussels Exchange. The French CAC40 had been calculated since 1986 and consists of top 40 stocks trading in the French Exchange. Both the indices follow a free float market capitalisation weighting mechanism. In the study, it is found that CAC40 is dependent on the movements in the Belgium Stock Exchange Index, BEL20. The Belgium index drives the French CAC40 index despite being a younger index. There had been a similar trend observed in the Indian indicesSensex and Nifty (Ghosh \& Srinivasan, 2015) and the Chinese Indices Hang Sen and Shanghai (Ghosh, 2016) wherein the younger index drives the older index. Therefore, further investigations need to be done in that regard.

\section{Applications}

The study can be used by the Qualified Institutional buyers (QIB), Foreign Institutional Investors (FIIs) and investors interested in using arbitrage opportunities. As of 2000, both CAC40 and BEL20 are a part of the largest European Stock Exchange, Euronext ("Euronext," n.d.). The outcome of the study can be taken up in future to study the impacts of such a driver - driven pair on Euronext and its related implications. The study can help the investors in refining their investment decisions by observing the movements of the driver index and accordingly steering their investments in the driven index thereby helping in making analyses for better investments and speculations. 


\section{References}

Arunachalam, S. K., \& Srividya, V. (2014). Stock Markets Inter-linkages among the two largest emerging economies of Asia - the case of India and China. Retrieved from https://www.researchgate.net/ publication/324648108_Stock_Markets_Inter-linkages_among_the_ two_largest_emerging_economies_of_Asia_-_the_case_of_India_and _China

Baharumshah, A. Z., Sarmidi, T., \& Tan, H.-B. (2003). Dynamic linkages of Asian stock markets. Journal of the Asia Pacific Economy, 8(2), 180-209. https://doi.org/10.1080/1354786032000074730

Bai, Z., Wong, W. K., \& Zhang, B. (2010). Multivariate linear and nonlinear causality tests. Hong Kong Baptist University HKBU Institutional Repository. Retrieved from https://repository.hkbu.edu.hk/ cgi/viewcontent.cgi?article $=1005 \&$ context=econ_ja

BEL 20. (2018). Retrieved from https:// markets. businessinsider.com/ index/bel_20

Bessler, D. A., \& Yang, J. (2003). The structure of interdependence in international stock markets. Journal of international money and finance, 22(2), 261-287.

CAC 40. (2018). Retrieved from https:// www.boursier.com/ indices/ composition/cac-40-FR0003500008,FR.html?tri=dcapi

Chen, G. M., Firth, M., \& Rui, O. M. (2002). Stock market linkages: evidence from Latin America. Journal of Banking \& Finance, 26(6), 11131141.

Choudhry, T., Lu, L., \& Peng, K. (2007). Common stochastic trends among Far East stock prices: Effects of the Asian financial crisis. International Review of Financial Analysis, 16(3), 242-261.

Darrat, A. F., \& Zhong, M. (2002). Permanent and transitory driving forces in the Asian-Pacific stock markets. Financial Review, 37(1), 35-51.

Euronext. (2018). Retrieved from https://www.euronext.com/en/we-areeuronext.

Ghosh, B., \& Srinivasan, P. (2015). A statistical analysis of the stochastic drift between Sensex \& Nifty-an in-Depth Study. International Journal of Innovative Research and Development, 4(5), 12-16.

Ghosh, B. (2016). Do the Dragons Move Together; Co-integrated and causality study among Chinese bourses- A curious case of Hang Seng and Shanghai Stock Exchange. https://doi.org/10.5958/22294503.2016.00010.2

Gupta, R., \& Guidi, F. (2012). Cointegration relationship and time varying co-movements among Indian and Asian developed stock markets. International Review of Financial Analysis, 21, 10-22. 
Al Asad Bin Hoque, H. (2007). Co-movement of Bangladesh stock market with other markets: Cointegration and error correction approach. Managerial Finance, 33(10), 810-820.

Hsu, L. H., Horng, W. J., \& Hsu, C. Y. (2012, May). An Influence of Canada Stock Market Factor on the Two Stock Market Returns: Study of the Hong Kong and the Singapore's Stock Markets. In Proceedings of the 2012 3rd International Conference on E-Business and E-GovernmentVolume 02 (pp. 140-144). IEEE Computer Society.

Huang, B. N., Yang, C. W., \& Hu, J. W. S. (2000). Causality and cointegration of stock markets among the United States, Japan and the South China Growth Triangle. International Review of Financial Analysis, 9(3), 281-297.

Jain, A. (2016). Reciprocity in Mutual Funds. Journal of Research in Business and Management, 4(8), 29. Retrieved from https:// www.researchgate.net/ publication/ 311352419_ Reciprocity_ in_ Mutual_Funds

Kim, Y., \& Shin, J. (2000). Interactions among China-related stocks. AsiaPacific Financial Markets, 7(1), 97-115.

Kishor, N., \& Singh, R. (2017). Contagion Effect among the BRICS Stock Market Indices. Journal of Poverty, Investment and Development, 31.

Mukherjee, P., \& Bose, S. (2006). A study of interlinkages between the Indian stock market and some other emerging and developed markets. In Indian Institute of Capital Markets 9th Capital Markets Conference Paper (p. 13). https:/ / doi.org/10.2139/ssrn.876397

Narayan, P., Smyth, R., \& Nandha, M. (2004). Interdependence and dynamic linkages between the emerging stock markets of South Asia. Accounting E Finance, 44(3), 419-439.

Niblock, S. J., \& Sloan, K. (2006). Are Chinese Stock Markets Weak-form Efficient? Southern Cross University. Retrieved from https:// www.researchgate.net/ publication/322819180_ Are_Chinese_Stock_ Markets_Weak-form_Efficient

Nikkei Indexes. (2018). Retrieved from https:// indexes.nikkei.co.jp/ en/ nkave/index/profile?idx $=$ nk225

Rehman, M. Z., Hazazi, M. A., \& Programe, M. S. F. (2014). Examining linkages between Saudi stock market (TASI) and selected stock market indices. International Journal of Financial Research, 5(4), 196-209.

Samadder, S., \& Bhunia, A. (2018). Integration between Indian Stock Market and Developed Stock Markets. Journal of Commerce and Accounting Research, 7(1), 13.

Shen, C. H., Chen, C. F., \& Chen, L. H. (2007). An empirical study of the asymmetric cointegration relationships among the Chinese stock markets. Applied Economics, 39(11), 1433-1445.

Sheng, H. C., \& Tu, A. H. (2000). A study of cointegration and variance 
decomposition among national equity indices before and during the period of the Asian financial crisis. Journal of Multinational Financial Management, 10(3-4), 345-365.

Smith, K. L., Brocato, J., \& Rogers, J. E. (1993). Regularities in the data between major equity markets: evidence from Granger causality tests. Applied Financial Economics, 3(1), 55-60.

Thalassinos, E. I., \& Politis, E. (2011). International Stock Markets: A Cointegration Analysis. European Research Studies Journal, l, 12(4).

Tian, G. G., \& Wan, G. H. (2004). Interaction among China-related stocks: evidence from a causality test with a new procedure. Applied Financial Economics, 14(1), 67-72.

TOPIX. (2018). Retrieved from https:// www.jpx.co.jp/ english/ markets/indices/topix/

Wessa, P. (2018). Free Statistics Software, Office for Research Development and Education, version 1.2.1.

Wong, W. K., Agarwal, A., \& Du, J. (2005). Financial integration for India stock market, a fractional cointegration approach. National University of Singapore Working Paper No. WP0501.

Yang, J., M. Khan, M., \& Pointer, L. (2003). Increasing Integration between the United States and other international stock markets? : A Recursive Cointegration Analysis. Emerging Markets Finance and Trade, 39(6), 3953.

Yusof, R. M, \& Majid, M. S. A. (2006). Who moves the Malaysian stock market - the U.S. or Japan?: Empirical evidence from the pre-, during, and Post-1997 Asian Financial Crisis. Gadjah Mada International Journal of Business, 8(3). https:// doi.org/10.22146/ gamaijb.5616

Zhu, H., Lu, Z., Wang, S., \& Soofi, A. S. (2004). Causal linkages among Shanghai, Shenzhen, and Hong Kong stock markets. International Journal of Theoretical and Applied Finance, 7(02), 135-149. 